\title{
Anomalous Heat Flow in the Pacilic Basin
}

from our Geomagnetism Correspondent THE discovery of high heat flow in the elevated marginal basins west of the major island arc chains in the western Pacific poses a problem for plate tectonics. At oceanic ridges, where new seafloor is being created by active intrusion associated with shallow water depths and tensional forces in the crust, high heat flow is both expected and found. In trench regions, on the other hand, where lithosphere is being destroyed and where compressive forces are supposedly dominant, zones of high heat flow conflict with the simple plate tectonic model.

There are several possible explanations, and whilst none is entirely satisfactory when examined in detail, not all can be confidently rejected. McKenzie and Sclater (J. Geophys. Res., 73, 3173 ; 1968), for example, showed that shear stress heating along the surface of the descending lithosphere is not sufficient because heat generated at depths below $300 \mathrm{~km}$ takes too long to reach the surface by conduction. The same workers also considered the effect of intrusion, notwithstanding the implied tension, but found that extension rates of up to $10 \mathrm{~cm} \mathrm{yr}^{-1}$ were necessary.

On the other hand, Karig (Bull. Geol. Soc. Amer., 82, 323 ; 1971 ; and J. Geophys. Res., 76, 2542; 1971) used morphological and sedimentary thickness data to conclude that the Philippine basin, the Parece Vela basin and the Mariana trough were formed in sequence by the intrusion of oceanic crust within $400 \mathrm{~km}$ of the active island arc-trench systems. As a result, he was able to suggest that the morphology, elevation, heat flow and crust of the western Pacific marginal basins could possibly be explained on the basis of episodic intrusion. For example, seismic reflexion profiles of the Mariana Island arc and the elevated Mariana trough show that the outer flanks of the arc are covered with thick sediment whereas there is almost no sediment in the interior of the basin. This absence of sediment, the presence of very fresh pillow lavas, the youth of drill cores and the narrow zone of shallow earthquakes along the centre of the trough combine to suggest that the basin was formed by recent intrusion.

The idea that the basins are old oceanic crust trapped behind a trench thus seems to be ruled out, and there is strong, but perhaps not conclusive, evidence for an extensional origin rather than formation in a compressional environment. There seems little doubt that an episodic intrusion process could be made compatible with rigid plate tectonics, as long as a large number of small plates are allowed between the intrusion zone and the trench. As Sclater (J. Geophys. Res., 77, 5705; 1972) has now shown, however, there is a problem in that the observed distribution of heat flow and crustal depth in the Pacific marginal basins is not consistent with a simple thermal model similar to the one capable of explaining high heat flow and elevation at ridges.

A few years ago, Sclater and Francheteau (Geophys. J., 20, 509; 1970) demonstrated that for the north Pacific and the south Atlantic there is a deflnite relationship between mean heat flow and the age of the oceanic crust produced at the spreading ridges, involving a decrease in heat flow from 2.8-2.2 $\mu \mathrm{cal} \mathrm{cm} \mathrm{cm}^{-2} \mathrm{~s}^{-1}$ for crust younger than

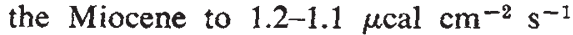
for crust older than about 100 million years. A similar correlation was later found to apply to the Indian Ocean. In addition, Sclater et al. (J. Geophys. Res., 76,7888 ; 1971) discovered a uniform crustal depth-age relationship for almost all oceanic ridges. Combining the two relationships gives a heat flow-depth correlation, although because of the scatter of heat flow values and uncertainties in depth it is a broad band setting outer limits.

If the basins were formed in the same way as oceanic ridges, they should plot within the broad band of the ridge heat flow-depth relationship. But although some do, a significant number does not. In the north-western Pacific, for example, only the Okinawa trough, the Yamato basin, the west Philippine basin and the north-western Pacific itself are consistent with ridge-type formation, and the Sulu and Parece Vela basins and the northern Japan abyssal plain show extreme departure from the heat flow-depth band. The Parece Vela basin is particularly interesting because two of the three drill holes in the area were put down there, and so the age of this basin is known. In this case a direct comparison with the ridge depthage relationship is possible and this too fails to produce a match. What all this amounts to is that many basins have too high a heat flow for their depth compared to the oceanic ridges-and the Parece Vela basin not only has too high a heat flow but is also too young.

Thus Sclater's general conclusion is that some of the north-western Pacific basins cannot have been formed by the process obtaining at oceanic ridges. This is not necessarily to say that intrusive processes have not been operating in the basins ; on the contrary, Karig's evidence strongly suggests that they have. But if they have, then that cannot be the whole story.
Three additional explanations are considered by Sclater. The first is to assume a higher thermal conductivity. The obvious way to change the thermal conductivity is to change the composition, but this is not valid here because it is already known that the composition of the crust and lithosphere in the marginal basins is the same as that of the ocean basins. But the thermal conductivity would be effectively raised if there were continuous incipient intrusion in the basin in addition to the lineated intrusion envisaged by Karig. The difficulties with this are, first, that shallow earthquakes would be expected from incipient intrusion, whereas these are not observed far from the trench axis, and, second, that it would represent a significant departure from rigid plate tectonics.

The second possible explanation is that originally put forward by McKenzie (Geophys. J., 18, $1 ; 1969$ ) to overcome the problem of heat conduction from below $300 \mathrm{~km}$, where the heat was assumed to come from the shear of the down-going plate in the Benioff zone. This is to postulate a thinner lithosphere under the marginal basins. For the present case the implications of this are that the basins are formed by lineated intrusion behind the arcs, but that as the crust moves away from the arcs it thins and hence loses its heat of intrusion faster than would otherwise be the case (for example, in the major oceans). Sclater's calculations show that this model is compatible with the high heat flow and elevation of the north-western Pacific marginal basins. There are still a few remaining problems with this model but they do not appear insuperable.

The final explanation refers to decreasing the elevation rather than accounting for excess heat. The idea here is to postulate a set of dynamic forces on the upper mantle landward of the trench resulting from the mass motion of the descending lithosphere. It may be, for example, that the marginal basins are not in isostatic equilibrium. A negative gravity anomaly would be expected in the marginal basins, however, where the dynamic forces are reducing the elevation, and yet none is observed. There are ways of solving this problem and there are other problems to be solved, but in Sclater's view a dynamic model cannot be discounted.

For the time being, Sclater prefers the thinner lithosphere model combined with lineated intrusion, but without closing the options on the other two explanations. As usual, more information is required, but given time the data needed should be easily obtainable. 